\title{
The Innovation-Remuneration Index (IRI). Making pharmaceutical companies report what matters about innovation.
}

\author{
Adam Cohen ${ }^{1}$, Rebecca Ultee ${ }^{1}$, and Glenn Veldhoven ${ }^{1}$ \\ ${ }^{1}$ Centre for Human Drug Research
}

February 23, 2021

\begin{abstract}
There is a lack of transparency about the cost of innovation of the pharmaceutical industry even though these costs are claimed to be the major driver for high prices for medicines. This is reflected by annual reports of the major pharmaceutical firms that contain a low number of pages on innovation and its detailed costs, in comparison to pages about remuneration of executives where the detail is excessive. The Innovation/Remuneration Index (IRI) provides an objective view of the transparency priorities of a company and has the potential to shift this focus in favour of transparent and detailed information on the cost of innovation.
\end{abstract}

\section{Hosted file}

Viewpoint vc01.pdf available at https://authorea.com/users/397649/articles/510463-theinnovation-remuneration-index-iri-making-pharmaceutical-companies-report-what-mattersabout-innovation 